\title{
En torno a la actualidad de Cosmópolis
}

\author{
Around the presence of Cosmopolis \\ Julio SeoAne Pinilla \\ Universidad de Alcalá \\ julio.seoane@uah.es
}

\begin{abstract}
Resumen. En torno al libro de Stephen Toulmin, Cosmopolis. The Hidden Agenda of Modernity se desarrollan tres tesis: (a) El cosmopolitismo, sobre todo el cosmopolitismo ilustrado, es base fundamental de los modos en como nuestras democracias se han desarrollado. (b) Tal cosmopolitismo fue una respuesta a un problema histórico que hoy ya no resulta lejano y, por ello, no es, tal cosmopolitismo, adecuado a nuestro presente. (c) Quizás sería de desear que nuestras justicia global considerara sus términos fundamentales con menos altivez y más sujetos a las negociaciones con otras tradiciones (no siempre cosmopolitas).
\end{abstract}

Palabras clave: cosmopolitanismo, justicia global, humanismo, Toulmin.

\section{1}

Que veinte años no son nada y apenas sí platean las sienes pero no menguan el sentimiento, es algo que nos llena de dulce melancolía cuando llega a nosotros en la rota melodía de un tango; que un libro que trataba de entender su momento histórico, tras veinte años siga describiendo de una manera exacta nuestro presente, es cuando menos inquietante si no desazonador. Aunque haya quien en ello vea el acierto de una obra. Esto es lo que ocurre con Cosmopolis: The Hidden Agenda of Modernity, uno de los últimos libros
Abstract. Around the Stephen Toulmin's book, Cosmopolis. The Hidden Agenda of Modernity, I would like to present three topics: (i) The Cosmopolitanism (mainly the Eighteen Century Cosmopolitanism) is the basis for the way our democracies has been implemented. (ii) This Cosmopolitanism was a situated answer for a historically contextualized problem; now this answer is very old and alien to our present. (iii) Taking the concepts of our global justice in a contingent and continually negotiated position, it is the best way in order to defend our democracies in a world were they are weak.

Key words: cosmopolitanism, global justice, humanism, Toulmin.

que publicó Stephen Toulmin ${ }^{1}$, justo hace veinte años, a fin de dar cuenta del mundo que a comienzos de los noventa se abría. Para ello optó no tanto por dar una explicación sociológica o apostar por algunas soluciones ante los problemas que entonces atenazaban a las democracias occidentales, cuanto por algo más simple, a saber, dar razón de por qué encaramos nuestra vida del modo en como lo hacemos y comprender que tal manera de actuar no es algo natural, sino una solución que en un momento de nuestro pasado se alzó para dar cuenta de ciertos problemas de estabilidad política y so- 
cial. Sí, incluso nuestra más alta filosofía, el modo en como la ciencia hoy trabaja, la manera en como concebimos nuestra naturaleza humana y nuestros derechos, posiblemente no se origine todo ello sino en una solución puntual a un problema de gobernanza nacional e internacional.

Tras el atentado contra las Torres Gemelas de Nueva York se podía oír la queja tan sentida como unánime y atónita de los neoyorquinos que no entendían por qué les odiaban. «¿Por qué nos odian?», «¿Qué hemos hecho nosotros?», eran exclamaciones que se escuchaban de manera continua en las fugaces tomas de impresión que los periodistas hacían a pie de calle en los días siguientes al brutal atentado. Nosotros, a este lado del Atlántico, entornábamos los ojos y con alguna displicencia les echábamos en cara su desconocimiento del mundo sobre el que soportaban su inocencia. Algo parecido le ocurría a Toulmin cuando miró a su alrededor y vio, algo más de una década antes de tan infausto atentado, un panorama semejante: nosotros pertrechados altivamente con nuestros Derechos Humanos, el convencimiento de que hay que «salvar el planeta», el deseo de establecer un Derecho Internacional, etc., a veces somos incapaces de ver más allá del mundo que hemos creado para nosotros y consideramos que no hay más que aquel pequeño reducto de edén que nos hemos fabricado. No digo que, por ejemplo, no debamos poner los Derechos Humanos como la frontera que indica que más allá está la barbarie y la inhumanidad, tan sólo pienso en este momento - y tras la relectura de Cosmópolis - que si tales derechos son tan escasa y reluctantemente adoptados fuera del «mundo civilizado» casi valdría la pena considerarlos no como un dogma que ha de acompañar todos nuestros discursos, sino como una manera - la nuestra- de entender el mundo y organizar la vida. Una manera que si desea establecerse (y eso hoy es esencial siquiera para asegurar lo que tenemos) debe entenderse como eso, como una manera y no como la manera; así, olvidando buena parte de su altanería, quizás fuéramos capaces de dialogar de igual a igual y no tratar de hacerlo de maestro a alumno (cuando no de sacerdote a fiel descarriado). Eso nos haría más convincentes sin lugar a dudas; y a buen seguro que defendería mejor nuestro cada vez más menguante mundo.

Pues bien, este es el fondo con el que empieza y con el que se cierra Cosmópolis. Entre tal comienzo y final Toulmin despliega con originalidad y claridad la explicación de cómo hemos fabricado nuestro mundo; ese mundo que hace veinte años, al igual que ahora nos ocurre, había manifestado una profunda crisis de todo aquello que lo componía (crisis del concepto de identidad, de la misma concepción del Estado, del orden cultural y científico...). Por otra parte, Toulmin era un hombre mesurado que no deseaba celebrar el caos, sino tan sólo entender por qué adviene precisamente ahora, por qué se hacía evidente que el maravilloso -y moral, y legítimo, y hasta emancipador - mundo moderno ya no valía en todos lados (o no era admitido con la generalidad que él mismo consideraba que debía ser admitido ante su belleza y justicia natural). Del mismo modo que nosotros pensábamos, ante aquellos aturdidos ciudadanos que exclamaban «ipor qué nos odian?» tras el bestial atentado que había hundido su ciudad (y buena parte de nuestro mundo), que quizás debieran mirarse al espejo con más detenimiento, Toulmin considera que las democracias occidentales quizás debieran hacer lo propio y preguntarse por qué motivo aquéllos que no aceptan nuestro maravilloso mundo de libertades y equilibrada justicia se repliegan en su oscura postura. Si nadie pone en duda que todo nuestro universo cultural, ético, político 
y hasta científico es un cosmos creado, creo que nadie se escandalizará por reconocer que (a) tal creación se hizo para responder a una situación concreta (que posiblemente ya no sea actual), ni por considerar que (b) puesto que nada hay de natural en nuestra vida nada más natural habrá que sea impugnada y deba saber negociar para establecerse en la compleja realidad en la que hoy habitamos. Reflexionar desde (a) pudiera enseñar que no pocos de nuestros más queridos valores ya no tienen uso ni utilidad; reconocer (b) quizás nos sitúe en un mundo donde cada vez perdemos más poder e influencia y en el que para subsistir ya no vale con creerse en posesión de todas las libertades y razones del mundo e imponerlas, y sea más pertinente reconocer la contingencia de todas nuestras imágenes y conceptos culturales, morales y políticos y ponernos — con conciencia - a negociar su subsistencia (lo cual es siempre más efectivo, por ser menos altivo, que ponernos - sin conciencia de ello- a predicarlos y obligar a comulgar con ellos).

\section{2}

Lo que hace interesante al libro de Toulmin es el hecho de que no hay que hacer muchos esfuerzos para ver nuestros días reflejados en la «crisis» desde la que él principia la Modernidad. ¿Qué crisis era aquélla? Toulmin sitúa su relato entre el XVI y el XVII, entre el comienzo del racionalismo y el ocaso del humanismo. Éste suponía que la diversidad era tal que no había otro modo de apechar con ella que concentrarnos en las pequeñas cosas, generalmente relacionadas con la vida cotidiana, y tratar de encontrar soluciones pequeñas y adecuadas al caso. Contingentes y frágiles. El modelo de esta actitud humanista es Enrique IV -Enrique de Navarra - que ejemplificaba, al decir de Toulmin, el intento de poder hablar con todos - sin tener en cuenta sus ideas religiosas ni actitudes políticas - y tratar de llegar a acuerdos en tales conversaciones. Acuerdos que no suponían una identidad irrenunciable, ni un fondo de común acuerdo y que pasaban por negociaciones en las que se entraba con la idea de que no existía ni un último consenso ni unos fundamentos irrenunciables. «París bien vale una misa» significaba no tanto la asunción maquiavélica de la pragmática política —que también es inherente al humanismo-, cuanto el hecho de que puestos a llegar a acuerdos nos vamos haciendo en esos acuerdos mismos y no somos algo que debamos ser siempre previamente a los mismos. No hay fijada de antemano una solución - aquélla que a todos conforme-, ni unos marcos de diálogo o deliberación, sino que aquélla y estos se van configurando en los pactos y consensos que la negociación va haciendo posibles. Y eso era el humanismo: una preocupación por las posibilidades prácticas de la vida humana que desplegaba un escepticismo tolerante al asumir que era imposible mediar de un modo definitivo con una solución. Por ello se trataba de vivir en las discusiones de la mejor manera de la que se pudiera disponer. Sería anacrónico considerar aquí que el humanismo estimaba - o celebraba - el conflicto como el lugar propio de la vida, pero no lo sería reconocer que lo aceptaba como el lugar propio del mundo humano. Sin ser adalides de la diferencia, Erasmo o Montaigne reconocían la necesidad de vivir en ella. De hecho la vida era, de una manera casi rortyana, simplemente saber apañárselas en un mundo tremendamente diferenciado y conflictivo.

Repito: la descripción que encontramos en Cosmópolis sobre el humanismo no nos ha de sonar muy lejana: un tono retórico ante la vida que puesto que considera que los problemas humanos son demasiado altos y lejanos para que me- 
rezca la pena discutir sobre ellos (desde nuestra pequeña, contingente y limitada racionalidad), apuesta por que lo mejor es discutir y tratar de conseguir algún acuerdo que no es sino un pequeño escalón, contingente, revisable y no último, que nos permita entendernos momentáneamente. Esta es la actitud de Enrique IV y su intento de lograr una vida entre partes diferentes e irreconciliables, pero que cuando menos pueden llegar a acuerdos para mantener su propia y diferente vida. Todos nos podemos entender para vivir juntos sin tener que renunciar a nuestra identidad y aun sabiéndonos diferentes e incluso enfrentados. Unos años antes de que Toulmin publicará este libro, I. M. Young había avanzado una utopía de vida multicultural — city life - muy semejante a ésta: los grupos diferentes se autoorganizaban entre ellos y establecían bases desde las que poder vivir en la ciudad en múltiples esferas culturales y políticas autónomas e inabordables a otras esferas culturales y políticas ${ }^{2}$.

Con todo lo amable que suela resultar la posición humanista, Toulmin nos recuerda que el XVII fue un siglo de guerras, hambres, enfermedades y en el que las disputas tanto como las censuras religiosas eran enormes. El asesinato de Enrique IV marca el fracaso de aquella utopía «postmoderna» avant la lettre. $\mathrm{Su}$ muerte señala que un mundo líquido donde el viajero montañista es un curioso que tan sólo mira y comenta para sí (para su propia estilización individual) es incapaz de organizar el mundo real en el que se vive: la guerra de los 30 años supone que las partes pueden hacer de todo menos acordar acuerdos estables y que las diferencias irreconciliables no se entienden a sí mismas si no es invadiendo toda la vida de los individuos y no limitándose a parcelas de tales vidas. Aceptar las diferencias y tratar de mediar tan sólo para que no se maten entre ellas, por muy atractivo ideal que pueda sonar a los oídos europeos contemporáneos, es olvidar que cuando tienen fuerza suficiente, los diferentes no aceptan la pérdida de ninguna de sus diferencias y es, al mismo tiempo, hacer oídos sordos a la evidencia de que tal mediación sólo se hace después de haber probado fuerzas (lo cual no se suele limitar a enseñar las garras).

El experimento fallido de Enrique IV puso a las claras que no había modo de que cohabitaran las facciones religiosas de buen grado, que no era posible vivir con la diferencia y que el escepticismo de Montaigne, o el «saber hacer» humanista, no eran capaces de evitar las muertes ni las luchas de religión (como no fue capaz Erasmo de dar un lugar donde católicos y protestantes pudieran vivir con sus distintas ideas): lo incierto se hizo inaceptable (p. 55). Tal que un gran atentado, la muerte de Enrique IV puso en evidencia que el estilo de la retórica (el todos pueden hablar postmoderno y multicultural), a fuerza de atender a lo pequeño y contextual (y de no tener una última instancia que garantizara un acuerdo duradero), no daba solución ninguna a las urgencias políticas nacionales ni internacionales. Ante aquel fracaso a partir de 1600 se dejan de lado las cuestiones humanistas, las relativas a las cuestiones más concretas de la vida cotidiana (que daban cuerpo a la retórica y al derecho civil) y el pensamiento se mueve hacia cuestiones más rigurosas, aquéllas que dirigirán a los pensadores hacia planteamientos más abstractos y universales que sacan a las situaciones analizadas de su contexto (y las consideran como si fueran experimentos que querían decir otra cosa); es el triunfo de la lógica sobre la retórica, de lo intemporal sobre lo temporal, de lo universal sobre la minucia montañista, de la ambición teórica sobre la modestia humanista (p. 43). 
cotidianeidad, que aun diciéndose con la voz que se dijera, tenía la posibilidad de

En un mundo asolado por las guerras de religión, donde era moneda común que bajo la misma creencia y semejante cosmovisión del mundo se plantearan diferencias irreconciliables que llevaban a la batalla a miles de hombres y empobrecían Europa, el empeño fue conseguir un punto donde se pudieran reunir los seres humanos y llegar a algún acuerdo que a todos aunara. Aquel etiamsi daremus de Grocio es reflejo de la apuesta por lograr un lugar de asentimiento común donde todos pudiéramos juntarnos a fin de poder establecer el inicio de la organización de nuestros asuntos cotidianos a partir de un mismo fundamento. Siendo éste la piedra angular sobre la que construir nuestra vida, las diferencias siempre podrán dirimirse remitiendo a tal clave que, por ser clara y distintamente aceptada, podrá ofrecernos un campo para solucionar nuestras diferencias (o el origen desde el que tal solución pudiera partir).

El yo que piensa y el pensamiento que desea establecerse limpiamente, no son sino la propuesta de esa clave (y del método o procedimiento en que todo se puede retrotraer a ella de un modo claro y distinto) desde donde se pueden construir todas las vidas etiamsi daremos Deum non esse. Esto es lo que conducirá, posteriormente, a Cosmópolis, un lugar que no es más que un sitio donde decidimos compartir el mismo método a fin de que todos, en su particularidad, puedan alcanzar idéntico conocimiento, conocimiento que es universal por ser el que emana del objeto - objetivo- sin interferencias - subjetivas - de ningún sujeto. Aquella región del Cosmos donde los hombres podían organizarse en torno a un gobierno común, como luego soñará Kant, suponía no tanto que todos habláramos con la misma voz, sino que todos estábamos por la labor de vivir en una ciudad, en una diendo su lejanía con el idioma madre. Dado tal esperanto, se trataba, repito, no de hablarlo, sino de tenerlo cerca y aceptar un procedimiento para usarlo de piedra de toque a la hora de legitimar, cuando ello hiciera falta, las palabras que pudiera hablar nuestro idioma particular (derivado de aquel esperanto, naturalmente).

Quizás pueda parecer excesivamente esquemático principiar todo nuestro mundo en este cambio del XVI y XVII; quizás algunos preferirían tomar en consideración otras aportaciones relevantes que el XVIII y el XIX supusieron o simplemente considerar de otro modo el origen de nuestra modernidad, pero realmente creo que el cuento de Toulmin funciona $\mathrm{y}$, al cabo, si tan sólo se trata de dar razón de la actitud «racionalista» o «científica» con la que hemos construido nuestros Estados-nación y el orden cultural que nos acompaña, esta no es mala manera. Y racionalismo tan sólo quiere decir que acudimos a resolver nuestros conflictos convencidos de que existe un fundamento, un orden, un «cosmos» por debajo de la diversidad de la polis; que el procedimiento deliberativo, que el estudio experimental y científico, que el intento de llegar a demostraciones objetivas, es preferible al arte de la retórica que implica que no hay verdad ni acuerdo ni resolución que dure más allá del momento en que se establece y firma. Una actitud racionalista que supone, en último término, que puede haber una firma que con otras acuerde sobre algo con la certidumbre de que todas esas firmas están decididas a considerar el documento firmado como la misma realidad que, de tal modo, queda establecida con Derecho, con garantías de que no va a ser ni cambiada ni rebasada a menos que se den argumentos, 
demostraciones y discusiones al alcance de cualquiera.

Era necesaria una certeza, un consenso racional y algo que asegurara la necesidad; y a ello se debió la estima que adquirió la teoría que se dirigía a lo claro y distinto. En definitiva, la pregunta por la certeza de los filósofos del siglo XVII no era un simple propósito de construir esquemas intelectuales abstractos y atemporales, imaginados como objetos de estudio intelectual puro; por el contrario era una respuesta contextualizada en un preciso desafío histórico, a saber, el caos político, social y teológico que supuso la Guerra de los Treinta Años. Como se ve un sistema frío, objetivo y que no se inmiscuía en las cuestiones de detalle precisamente para resolver las cuestiones de detalle: "vista en su contexto, el movimiento racionalista de descontextualizar los problemas de la ciencia y de la filosofía y de usar los métodos de la lógica formal y de la geometría como fundamento para la resolución racional de los problemas físicos y epistemológicos, era más que un estimable experimento del método filosófico. Era también un movimiento político oportuno» (p. 80). Pues bien, es aquí donde reaparece con energía la idea de Cosmópolis, una palabra-concepto que pone en funcionamiento John Donne para hablar de una unión del Cosmos y de la Polis, algo que sea capaz de unificar el gobierno de la Naturaleza con la naturaleza humana ${ }^{3}$, que permita abandonar el escepticismo tranquilo de Montaigne y la retórica naif humanista y obtener, a cambio, una vigorosa idea del mundo desde la cual abandonar la corrupción y miseria de un presente, como el del XVII, tan caótico $\mathrm{y}$ en crisis como nuestro propio tiempo.

A partir de 1640, en los Estados-nación que se formaban la palabra era estabilidad y Cosmópolis la ofrecía: no cohabitar en la retórica (en la negociación, en el reconocimiento de que no hay una verdad última sino una eterna discusión y consensos momentáneos), sino buscar un punto de universal aquiescencia. Cosmópolis era un modelo en el que el orden social se mantenía porque era reflejo de un orden cósmico y universal; un orden que afectaba a todos los cuerpos, pues por debajo de sus diferencias la razón — tan emancipada como ajena a intereses, pasiones y engaños - hallaba una ley común que a todos ordenaba y que, además, hacía que todo (y todos) se entendiera a partir de tal ley. En resumen: si Cosmópolis es la idea de que el orden del Cosmos se debe reflejar en la ciudad de los hombres, esta, de tal modo, puede obtener un fundamento tan firme y seguro como aquel. A partir de aquí el cosmopolita es un ciudadano global no en el sentido del viajero montañista que viaja y mira, sino en el de quien sabe que hay un orden y él pertenece a tal orden (como luego acontecerá con uno de los adalides del cosmopolitismo, incluso no hará falta salir de casa para sentirse cosmopolita). Pero, tanto como un ciudadano del mundo, también es, el cosmopolita, el ciudadano de un Estado-nación, donde el rey, como el sol, gobierna todo el movimiento de los elementos sociales: bien podemos ser diferentes y diversos (con distintas energías y capacidades e intereses), pero existe una naturaleza que a todos nos une $\mathrm{y}$ vincula, que nos hace iguales y libres en la medida en que nos apercibimos - y por ende aceptamos - del orden justo y natural. Frente a la retórica humanista que buscaba acuerdos entre partes que no renunciaban a sus diferencias, el intento de Cosmópolis es buscar un punto de indubitable aquiescencia, un lugar, tan claro y distinto que nadie pueda poner en duda. Un punto de partida desde el que todos acordemos en utilizar el mismo camino «aun en el caso» de que no creyéramos en el mismo Dios. 
Visto así, hallar el orden de la ciudad como el trasunto de un orden cósmico ya no es sólo una cuestión intelectual que presente el universalismo frente al escepticismo amable de Montaigne o la demostración racional frente a la bella retórica humanista, es, sobre todo, la propuesta de un Estado-nación estable, cual planeta en el orden cósmico; es el lugar donde los conflictos tienen asegurada su resolución no por imposición o por pragmática política, sino por común aceptación. Esta común aceptación será lo que, con el tiempo, se transformará en la misma base de la autonomía individual y la legitimidad de los Estados tanto como de sus acuerdos internacionales. Como se ve, algo muy alejado de la negociación inconstante y sometida a revisión del mundo humanista y mucho más cercana al mundo en el que efectivamente hemos construido nuestra misma noción de identidad personal y social ${ }^{4}$.

\section{4}

No creo que haga falta recalcar lo que la noción de ley universal (¿cabe imaginar otra?) supone. «Todos» estamos ordenados bajo la misma ley (sea física o moral) y por ello «todos» - y aquí estribará la libertad a poco - afirmamos la misma ley (que por única y evidente, clara y distinta, es justa). Ningún lugar más común a nuestra propia comprensión del mundo: (a) todos somos iguales y (b) somos iguales porque no somos diferentes, porque en definitiva, en su fundamento, en su origen, tenemos una naturaleza que dice lo mismo.

Quiero insistir de nuevo en que podemos conceder que Toulmin no tiene razón, que quizás explicar el surgimiento de la actitud racionalista moderna como respuesta a un problema histórico sea tergiversar nuestro mundo, incluso podemos rechazar que la base del proceso que persiguió la objetividad y el conocimien- to ajeno a intereses e ídolos tuviera siquiera un propósito y no fuera, antes bien, la base de nuestra propia naturaleza lo que con tal proceso se pusiera en claro, pero, con todo, en nada habríamos impugnado lo que Cosmopolis presenta. Porque aunque su visión histórica yerre no lo hace así su definición de un mundo cosmopolita que es, en definitiva, el mundo donde se puede reclamar un Derecho y una Justicia universal: el ciudadano cosmopolita es un ciudadano del mundo en tanto que reconoce que su ciudad ha de regirse por la misma ley que cualquier otra ciudad, que no hay más que un derecho que las variaciones y diferencias pueden modificar, pero no alterar en su esencia. La idea de poder ser de todos lados sin salir de casa - tanto como la de poder caminar por todos lados y ver siempre la propia casa - es la que inaugura un cosmopolitismo que nada tiene que ver con los viajes de Montaigne o con el mundo de los viajeros que se llamaban ciudadanos del mundo simplemente porque gustaban de viajar y asombrarse con lo diferente (y no porque consideraran la posibilidad de una «ciudadanía» universal).

\section{5}

Si bien es cierto que Cosmópolis es palabra-concepto que aparece en el lugar que Toulmin comienza a reconstruir nuestro presente, no es menos verdad que a la hora de hablar de cosmopolitismo es al XVIII a donde no sin razón solemos mirar. Y quizás sea en Kant en donde se ejemplifique de mejor manera el cosmopolitismo del que nos hacemos herederos. Es bien cierto que no es la única voz que apuesta por una ciudadanía cosmopolita en un siglo, el de las luces, en el que realmente se oye la confesión «yo soy un ciudadano del mundo» en muy diferentes personajes, pero no es menos verdad que posiblemente sea en Kant donde mejor se deja ver, y de manera más lúcida, lo que 
el cosmopolitismo, recogido desde su herencia estoica, puede aportar a la composición de la modernidad. Con todo, no debemos olvidar que también es común en el XVIII una adhesión al cosmopolitismo realizada desde la apuesta cínica. Desde tal posición no es aquello en común que tenemos entre los hombres lo que se subraya (aquel sentirse en casa porque mi casa es el mundo entero), sino el mismo hecho de que puesto que no hay casa ninguna, cualquier sitio es bueno para pasear nuestra vida 5 .

Como sea, lo cierto es que un ciudadano del mundo que por doquier ve su propia casa (con diferencias, mas sin variaciones fundamentales) quizás pudo organizar la Modernidad y nuestras democracias con sus irrenunciables ventajas, pero cualquier hoy puede sentirse violentado desde fuera, desde las diferencias a las que se ha de forzar a ver que no son tales o que no lo son de un modo fundamental; porque, realmente, la ley que se hace ver, la que se explicita con la ciencia moderna y sus modos de racionalizar y explicar la realidad (o con la democracia y la vida que impone desde hace ya algunas décadas) nos parece una universalidad muy controvertible. Efectivamente, ya a principios del siglo xx la diversidad (que aparece incluso en las mismas ciencias) resulta tal que hace imposible mantener el sueño de un Cosmos ordenado según una misma ley. El evolucionismo, Freud, la antropología, las nuevas ciencias, un sinfín de situaciones que el mismo Toulmin recopila para mostrar que en 1910 la variedad era tan grande que la «Europa occidental estaba al borde de regresar al mundo de la moderación política y la tolerancia humana que había sido el sueño de Enrique IV y de Montaigne»» (p. 151). Pero la evidencia de que a comienzos del siglo xx ya se debía cambiar el sueño de Cosmópolis por otro diferente quedó olvidada de nuevo por una situación política internacional que hizo pa- tente la necesidad de un orden «cosmopolita». Podemos advertir un convincente paralelo entre 1630 y 1930: las dos guerras mundiales y posteriormente la guerra fría no eran el ambiente más propicio para olvidar un lugar de común resolución de conflictos por otro de retórica y diferencia; mala era la situación para jugar a la locura del surrealismo, del dadaismo o de los mundo probables e incluso diferentes tal y como aparecían en las nacientes teorías científicas. Lo cierto es que la quiebra de Cosmópolis no podía demorarse más y ya a partir de los sesenta y de los setenta comienza el gran cambio: se pone de manifiesto que no hay lugar para una sola ley, que incluso el Cosmos era demasiado complejo como para regirse con una sola voz y nuestra misma comprensión de la ciencia deja de ser unificada (el plural —las ciencias - comienza a ser utilizado poniendo en claro que cada ciencia tiene un diferente método de acercamiento a su objeto); también dejamos de ser tomados como elementos racionales económicos $\mathrm{y}$, con Freud, aceptamos las pasiones y no distinguimos entre mente y cuerpo - con ello comenzamos a considerar que la razón no debe ser en todo punto racional y aprendemos hasta a razonar «ecológicamente»-; es, todo ello, el comienzo de una nueva era donde volvemos a revalorizar posturas como la de Montaigne.

\section{6}

Pero seamos justos: no es tanto que la crítica intelectual y el desarrollo científico hayan vuelto a poner a Montaigne dentro de nuestros intereses, cuanto que el orden mundial ha variado y ya no nos es fácil imponer la visión cosmopolita. La ciudadanía universal quiebra cuando el universal se desvela tremendamente controvertible y la misma noción de ciudadanía resulta que se entiende desde una perspectiva muy particular. En este sentido la 
óptica que nos presta Toulmin es capaz de componer una cámara capaz de darnos una excelente $-\mathrm{y}$ útil, y explicativafotografía de nuestra realidad ética, política, cultural y científico-técnica; realmente su interés era recordarnos lo que para aquéllos que nos oyen (que oyen nuestra voz en el FMI, en la OCDE o en cualesquiera de aquellos altavoces del mundo de Cosmópolis) resultaba evidente.

Si el mundo de Cosmópolis hoy se nos hace difícil de pensar desde el mismo mundo que Cosmópolis crea, desde los Estados-nación, también, en una perspectiva internacional, el mundo de la ciudadanía universal que surge al hilo de la apuesta por la razón moderna es complicado de mantener tal cual, sobre todo a poco que atendamos a la evidencia del hecho de que otros países piden voz y si bien hasta ahora se les «obligaba» a pasar por Cosmópolis y por las diferentes organizaciones con las que hemos creído desarrollarla, ellos ahora tienen fuerza y no desean leer sólo a Descartes. Y la palabra es «fuerza». No es que ahora oígamos otras voces, es más bien que éstas ahora tienen el poder para imponerse, para chillar lo suficientemente alto y poderosamente como para exigir que nosotros las atendamos no como un ruido, sino como un idioma. Ésa fue una de las paradojas de Cosmópolis, el hecho de que se propuso como un idioma universal para entenderse entre todos, pero tal idioma, creado para responder a una serie de problemas históricos concretos, muchas veces era difícil tomarlo sino como un idioma muy ajeno al propio (idioma que se terminaba imponiendo a la propia lengua). Hasta no hace mucho se solía decir que lo que se imponía no era nada que no fuera la misma humanidad, el lenguaje que naturalmente corresponde al hombre, pero hoy sabemos que no es sencillo legitimar el hecho de obligar a hablar en moderno en todos los sitios.
La misma razón de nuevo recibe la duda que Pascal alzó contra Descartes: ¿es la razón algo tan poderoso como para dar razón de un mundo complejo (como para ser piedra angular de nuestro mundo)? Nacionalismos y fundamentalismos piden paso para entrar en nuestra política y negárselo, con las claves con las que Descartes presentó nuestro mundo, cada vez nos es más complicado. Y no sólo es la aparición de argumentaciones alejadas de la razón que el XVII creó, es también el hecho de que cada vez con más evidencia se plantea que es la fuerza la que ha de acompañar a tal razón. Ora un golpe en la mesa que establece la ciudadanía en tal o cual país (ya sin necesidad de una noción de ciudadanía cosmopolita), ora una invasión o una amenaza ante voces «no ilustradas», son variados y no escasos los momentos en que, de nuevo, la duda de Pascal triunfa: la razón sola es demasiado débil, una minusválida para organizar el mundo de los seres humanos.

Cosmópolis se tambalea porque sólo los más viejos del lugar creen que exista algo universal que subyace a todo. Pero si todo el fundamento teórico de Cosmópolis se puso en duda en los años setenta y ochenta; todo su fundamento ético y político se pone en duda con unos procesos económicos que han transformado Cosmópolis en un mundo globalizado donde el «idioma universal» ya no es la razón para entendernos entre los seres humanos, sino la herramienta para imponer un mercado impersonal que no supone el acuerdo universal, sino simplemente el consumo generalizado. Si uno recuerda el reparto colonial que en el XIX se hizo del mundo, podrá considerar que ciertamente Cosmópolis nunca fue sino una excusa para establecer un estado de paz estable (no justo, sino donde sencillamente se ponía el pie sobre los demás de una manera estable); eso es lo que se nos echa en cara con fuerza a quienes pensábamos 
que un mundo cosmopolita era el culmen de la justicia universal y ahora nos es difícil dar razón de nuestra «ingenua» creencia. Es verdad que en algún momento el cosmopolitismo aparece como la admisión de que todos los humanos tenemos siempre en común no tanto una ley o una naturaleza cuanto un deseo de querer ser felices, de poder vivir con dignidad, de explicar nuestros actos cuando se nos afronta algo, etc. ${ }^{6}$, pero esta forma más light y amable que hoy el cosmopolitismo puede adoptar (yo, nacido en París, vivo en Tánger y viajo habitualmente por Europa y Estados Unidos) no tiene nada que ver con la exigencia de Cosmópolis. De hecho o se hace similar al viajero de Montaigne (ese curioso que viaja sencillamente para decirse a sí $\mathrm{y}$, al tiempo, decir desde sí algo sobre el mundo) ${ }^{7}$ o vuelve a poner sobre la mesa derechos inalienables del ser humano independientes del país, de la casa donde habiten (país y casa generalmente amueblados ambos merced a una globalización impuesta).

En su día Toulmin consideró que ante el mundo que se le abría la postura ideal era hacernos hijos tanto del racionalismo que comienza con Descartes cuanto del Humanismo que se perdió con él (pp. 180-181), pues ahora nuestro interés ya no es la estabilidad y uniformidad, sino proteger la diversidad y adaptabilidad. Tener nostalgia de la vieja Cosmópolis es olvidar en qué se apoyaba: el sol $\mathrm{y}$ sus planetas se reflejaba en el rey sol y sus vasallos. Y eso ya no nos convence pues «en una época de interdependencia y cambio histórico, la mera estabilidad y permanencia ya no es suficiente» (p. 186), de ahí nuestro retorno filosófico y teórico a lo oral, a lo local, a lo particular y ello sin querer dejar de lado la gran teoría que nos ha dado a luz, la interdependencia que nos hace universales. Toulmin en su momento no veía más so- lución que una cosmópolis ecológica, donde el modelo no fuera la física sino la compleja vida, donde todo estuviera conectado sin que se renunciara a la particularidad del individuo. No se trata de olvidar el Estado-nación sino simplemente plantear que no pocas veces tiene intereses que no son naturales ni fundamentados. Y sobre todo recuperar lo razonable frente a lo racional, hacer hincapié en lo temporal, en la pequeña escala, en el hecho de que la justicia ya no vendrá bajo el modelo de Cosmópolis, pero sí deberá ser cosmopolita: deberá viajar, hablar y tratar de recoger lo pequeño en lo global, lo cual, en política, quizá sea no olvidar Liliput: «Por último, atendiendo a lo transnacional, no olvidemos Liliput. Las comunidades locales y los grupos no representados necesitan medios de autoexpresión y protección... en la tercera fase de la Modernidad, el nombre del juego será influencia y no fuerza y, jugando en este terreno, los liliputienses tienen ciertas ventajas» (p. 208).

El esperanzado mensaje con el que finaliza el libro de Toulmin quizá hoy nos suene demasiado optimista y esa es realmente la diferencia que marcan los años transcurridos entre la publicación de Cosmópolis y nuestros días. Lo que hemos aprendido en un par de décadas es que no sabemos realmente como mirar a la pequeña escala y conservar al mismo tiempo el mundo en el que vivimos y al que no deseamos renunciar (para, sin ir más lejos no perder nuestra misma noción de Justicia). Que la justicia ha de ser global parece hoy evidente, pero ¿cómo hallar el mismo marco de la discusión global siquiera de cuáles han de ser los problemas a discutir?¿Cómo imaginar un Tribunal Penal Internacional sin un consenso fuerte, sin la firma definitiva de todos? Que otros países entren en la discusión internacional, tal y como hoy acontece y Toulmin anuncia- 
ba que era inevitable, nos deja, de nuevo, en una época de confusión donde el remedio del XVII ya no vale porque lo hemos finiquitado. Y donde el escepticismo humanista, como entonces, trae problemas y además (y posiblemente más importante) no es desarrollado por todos. En estos términos el viajero nos es curioso pero insoportable y el cosmopolita kantiano supone demasiadas cosas poco cosmopolitas. Como se intuye, la solución es compleja.

\section{NOTAS}

1 Stephen Toulmin, Cosmópolis: The hidden Agenda of Modernity, Nueva York, Free Press, 1990. (Cosmópolis: el trasfondo de la Modernidad, Barcelona, Península, 2001). A partir de ahora las citas de este libro se harán directamente en el texto con el número de página de la edición original entre paréntesis.

2 Los acuerdos, como en el caso de Enrique IV, no han de suponer renuncia a la propia identidad y puesto que en la ciudad moderna es inevitable la diferencia y el conflicto, se trata de minimizar las relaciones entre diferentes y reducirlas a aquellos acuerdos desde los que unas partes dejen autoorganizarse a aquéllos con los que no comparten pedazos de ciudad. Esto que se puede ver en I. M. Young, Politics and the Politics of Difference (Princeton University Press, 1990) también lo podemos encontrar en otros lugares, como por ejemplo A. Phillips, Politics of Presence (Oxford, Clarendon Press, 1995) y asoma en la mayoría de las discusiones de la pasada década sobre cuestiones multiculturalistas.

3 John Donne (1572-1631) es un poeta inglés (caracterizado como "poeta metafísico») de un marcado talante contra-renacentista. Emplea por vez primera el término «cosmópolis» para enfrentarse a la nueva ciencia que desde Copérnico y Kepler se estaba proponiendo. Lo hace a partir de su poema An Anatomy of the World (1611).

${ }^{4}$ Así se puede leer, también, el intento de Leibniz con su simbolismo matemático o al buscar un lenguaje ideal con el que los hombres podrían razonar juntos sin miedo a equivocarse y podrían, con ello, entenderse; y se puede leer, también y sobre todo, el mundo de Newton capaz de llevar a cabo la escisión entre materia y espíritu y de ver la materia como el cuerpo de los carácteres — ciertos y verdaderos- matemáticos.

5 Esta contraposición se desarrolla con claridad en el revelador artículo de Rebecka Lettevall, «The idea of Kosmopolis: Two kinds of Cosmopolitanism» incluido en R. Lettevall \& M. K. Linder (eds.), The Idea of Kosmopolis, Södertörns Academia Studies 37, Hudinge (Suecia), 2008

${ }^{6}$ Ver aquí, por ejemplo, K. A. Appiah, Cosmopolitismo. La ética en un mundo de extraños, Buenos Aires, Katz, 2007.

7 Posición que mostrará al XVIII francés de modo ejemplar Fougeret de Monbron en su El cosmopolita o el ciudadano del mundo que en 1750 plantea la posición del cosmopolitismo cínico de la que antes hablé de un modo ejemplar y quizás de una manera mucho más contemporánea que el caso de Montaigne: «Todos los países me son iguales siempre que pueda disfrutar en libertad de la claridad del cielo y que pueda mantener convenientemente a mi persona hasta el final de mis días» [Fougeret de Monbron, Le cosmopolite ou le citoyen du monde, MHRS (Modern Humanities Research Association) n. ${ }^{\circ}$ 22, 2010 (El cosmopolita o el ciudadano del mundo, Pamplona, 2011)]. 